\title{
The RNA polymerase II subunit Rpb4p mediates decay of a specific class of mRNAs
}

\author{
Rona Lotan, Vicky Goler Bar-On, Liat Harel-Sharvit, Lea Duek, Daniel Melamed, and \\ Mordechai Choder ${ }^{1}$ \\ Department of Molecular Microbiology, Rappaport Faculty of Medicine, Technion-Israel Institute of Technology, \\ Haifa, Israel 31096
}

\begin{abstract}
It is commonly appreciated that the mRNA level is determined by the balance between its synthetic and decay kinetics. Yet, little is known about coordination between these distinct processes. A major pathway of the eukaryotic mRNA decay initiates with shortening of the mRNA poly(A) tail (deadenylation), followed by removal of the mRNA 5' cap structure and its subsequent exonucleolytic degradation. Here we report that a subunit of RNA polymerase II, Rpb4p, is required for the decay of a class of mRNAs whose products are involved in protein synthesis. Cells lacking $R P B 4$ are defective in the deadenylation and post-deadenylation steps of representatives of this class of mRNAs. Moreover, Rpb4p interacts with both the mRNP and with subunits of the mRNA decay complex Pat1/Lsm1-7 that enhances decapping. Consistently, a portion of Rpb4p is localized in P bodies, where mRNA decapping and degradation is executed, and mutations in $R P B 4$ increase the number of $P$ bodies per cell. We propose that $R p b 4 p$ has a dual function in $\mathrm{mRNA}$ decay. It promotes or enhances the deadenylation process of specific mRNAs and recruits Pat1/Lsm1-7 to these mRNAs, thus stimulating their decapping and further decay. In this way, Rpb4p might link the activity of the basal transcription apparatus with that of the mRNA decay machinery.
\end{abstract}

[Keywords: mRNA decay; P bodies; RNA polymerase II; RPB4; RPB7]

Supplemental material is available at http://www.genesdev.org.

Received May 24, 2005; revised version accepted October 27, 2005.

Gene expression is a complex process that involves several distinct stages, each of which is subject to tight controls. Previous works from many laboratories revealed that the regulation of the various stages is coordinated or "coupled". Thus, each stage can be regarded as a subdivision of a continuous gene expression process. Coupling between mRNA synthesis and its export (Vinciguerra and Stutz 2004) and between translation and mRNA degradation (Jacobson and Peltz 1996; Schwartz and Parker 1999; Coller and Parker 2004; Wilusz and Wilusz 2004) have been demonstrated in several laboratories. However, relatively little is known about the possible coupling between transcription in the nucleus and mRNA degradation in the cytoplasm.

mRNA turnover is an essential and well-controlled component of the gene expression process. The half-lives of yeast mRNAs vary substantially, from $3 \mathrm{~min}$ to $>100$ min (e.g., see Wang et al. 2002; Grigull et al. 2004). However, the degradation rates within a group of mRNAs are sometimes found to be alike. Examples of mRNA groups

${ }^{1}$ Corresponding author.

E-MAIL choder@technion.ac.il; FAX (972) 4-829-5225.

Article and publication are at http://www.genesdev.org/cgi/doi/10.1101/ gad.353205. are mRNAs encoding proteins that constitute common complexes and mRNAs encoding proteins that have overlapping cellular roles (Wang et al. 2002). Moreover, mRNAs encoding functionally related proteins exhibit a similar degradation profile in response to environmental signals (Garcia-Martinez et al. 2004; Grigull et al. 2004). These observations highlight the significant influence of mRNA decay on regulation of gene expression and raised the concept of "decay regulons" (Garcia-Martinez et al. 2004). One prominent decay regulon in yeast consists of mRNAs encoding ribosomal proteins (RP-mRNAs) (Wang et al. 2002; Garcia-Martinez et al. 2004; Grigull et al. 2004).

In yeast, a major pathway of mRNA degradation initiates with deadenylation of the mRNA poly(A) tail whose full length in yeast is usually 60-80 bases (Brown and Sachs 1998; Mangus et al. 2003). When the length of the poly(A) tail reaches 10-12 bases or less, the mRNA 5' cap $[\mathrm{m}(7) \mathrm{GpppN}]$ is removed (Decker and Parker 1993) followed by an exonucleolytic digestion of the unprotected RNA. Deadenylation is carried out by Pan2p/ Pan3p and the Ccr4p/Caf1p poly(A) nuclease complexes (Tucker et al. 2001, 2002), while decapping by Dcplp/ Dcp2p (Parker and Song 2004). Decapping is probably a point of no return in the degradation process, as it ex- 
poses the $5^{\prime}$ end of the mRNA to the major $5^{\prime}$-to- $3^{\prime}$ exonuclease, Xrn1p, and facilitates its activity. Several proteins regulate the decapping process, including Patlp. Patlp is considered to be the first decay factor recruited to mRNA, at a time when the mRNA is still associated with translation factors (Tharun and Parker 2001). Subsequently, Patlp recruits the hepta-heterodimer Lsm1-7 complex (Coller and Parker 2004). Lsm1-7 complex and its associated factors are important for efficient decapping, probably due to their influence on RNP architecture and on accessibility of the cap structure /Coller and Parker 2004) and possibly by their direct effect on Dcp1/ Dcp2 activity (Zhang et al. 1999). It is still unclear how the degradation factors are recruited to mRNA and what controls this recruitment. In particular, it is not clear how Patlp is recruited to the mRNA.

Recently, it was discovered that mRNA decay intermediates are found in specific yeast cytoplasmic foci, termed P bodies (Sheth and Parker 2003; Teixeira et al. 2005). These foci also accommodate proteins involved in mRNA decapping and 5'-to-3' exonucleolytic degradation (Sheth and Parker 2003). Hence, P bodies likely represent sites wherein mRNAs are decapped and degraded. Analogous structures have been observed in mammalian cells, suggesting that $\mathrm{P}$ bodies are required for a conserved mechanism (Bashkirov et al. 1997; Ingelfinger et al. 2002; Lykke-Andersen 2002; van Dijk et al. 2002).

The decay rates of mRNA are affected by a variety of stimuli, including hormones (Ross 1996), starvation (Jona et al. 2000; Yin et al. 2003; Garcia-Martinez et al. 2004), cell cycle progression (Morris et al. 1991), and cell differentiation (Jack and Wabl 1988). Nevertheless, we have begun to appreciate only recently that some degradation factors might have a selective role in the decay program in that they act only on a subset of mRNAs (Badis et al. 2004; Grigull et al. 2004). In particular, the degradation of mRNAs encoding ribosomal proteins (RP) and ribosomal biogenesis regulons (Ribi) seems to be mediated by specific factors. For example, the decay factor Ccr4p contributes to the degradation of this group of mRNAs more than it does to other mRNAs (Grigull et al. 2004). Interestingly, Ccr4p is also a transcription factor (Collart 2003).

The RNA polymerase II (pol II) is composed of 12 subunits (termed Rpb1p-Rpb12p) (Young 1991). Crystal structures of the 12 subunits of the yeast pol II have been resolved recently (Armache et al. 2003; Bushnell and Kornberg 2003). The structures reveal that the 12-subunit enzyme consists of two distinct parts. The first is a 10-subunit core that constitutes the bulk of the pol II structure and includes the catalytic active site. The second part is a two-subunit heterodimeric complex composed of $\mathrm{Rpb} 4 \mathrm{p}$ and $\mathrm{Rpb} 7 \mathrm{p}$ (for a recent review, see Choder 2004). The 10-subunit core structure has been studied intensively, whereas $\mathrm{Rpb} 4 / 7$ has received less attention.

$\mathrm{Rpb} 7 \mathrm{p}$ is an essential protein (like most pol II subunits) (McKune et al. 1993; Mitsuzawa et al. 2003). Rpb4p is essential for transcription only under some adverse conditions, but is dispensable under optimal environmental conditions (Woychik and Young 1989; Choder and Young 1993; Khazak et al. 1995; Sheffer et al. 1999; Tan et al. 2000; Miyao et al. 2001; Farago et al. 2003). Rpb4p is present in excess over Rpb7p, suggesting that the former might carry out some of its functions independently of the latter (Choder 2004). Previously, we found that $\mathrm{Rpb} 4 \mathrm{p}$ is required for mRNA export to the cytoplasm (Farago et al. 2003).

Here we report two novel functions of $\mathrm{Rpb} 4 \mathrm{p}$ in mRNA decay. The effect of Rpb4p on mRNA turnover is specific to mRNAs whose products are involved in protein synthesis. Our observations implicate Rpb4p as a factor that couples and possibly coordinates between the nuclear and cytoplasmic stages of gene expression, but that influences only a subset of mRNAs.

\section{Results}

Rpb4p is required specifically for the decay of mRNAs encoding ribosomal proteins and translation factors

We have demonstrated previously that Rpb4p can be found both in the nucleus and in the cytoplasm (Farago et al. 2003). The presence of Rpb4p in the cytoplasm raised the possibility that $\mathrm{Rpb} 4 \mathrm{p}$ has a function also in this compartment. To investigate this possibility, we employed a two-hybrid approach to determine whether Rpb4p interacts with cytoplasmic factor(s). We found that Rpb4p interacts with the mRNA decay factor Pat $1 p$ (data will be presented later in Fig. 8, below), suggesting that $\mathrm{Rpb} 4 \mathrm{p}$ may be involved in mRNA decay. To test directly whether Rpb4p influences mRNA turnover, we examined mRNA decay kinetics in wild-type cells and in cells lacking RPB4 (rpb4 4$)$ at both $24^{\circ} \mathrm{C}$ and $37^{\circ} \mathrm{C}$. These temperatures were chosen since, at $24^{\circ} \mathrm{C}, \mathrm{Rpb} 4 \mathrm{p}$ is dispensable for viability, while at $37^{\circ} \mathrm{C}, \mathrm{Rpb} 4 \mathrm{p}$ is essential for transcription and for mRNA transport (Choder 2004). We blocked transcription using 1, 10 phenanthroline and mRNA degradation was determined thereafter. Phenanthroline was selected because it permits us to perform the experiment at various temperatures and analyze many different mRNAs simultaneously. The effect of this drug was recently assessed by systematic and thorough whole genome analyses. Degradation kinetic results obtained with 1, 10 phenanthrolin, thiolutin, and 6-azauracil correlated very closely to each other (Grigull et al. 2004), in spite of their different modes of action. In each of our experiments the drug was added while cells proliferated at $24^{\circ} \mathrm{C}$, when most mRNAs of both wildtype and $r p b 4 \Delta$ cells were in the cytoplasm (Farago et al. 2003). In experiments where we were determining degradation kinetics at $37^{\circ} \mathrm{C}$, the cells were shifted to this high temperature after drug administration. This experimental design allowed us to follow specifically the degradation kinetics of the cytoplasmic mRNAs.

The degradation kinetics of RPL25 and NSR 1 mRNAs, encoding RP and Ribi proteins, respectively, were fast in wild-type cells at $24^{\circ} \mathrm{C}$ (Fig. 1A). The relatively short half-life of these mRNAs is consistent with published data (Herruer et al. 1988; Wang et al. 2002) and is a fea- 

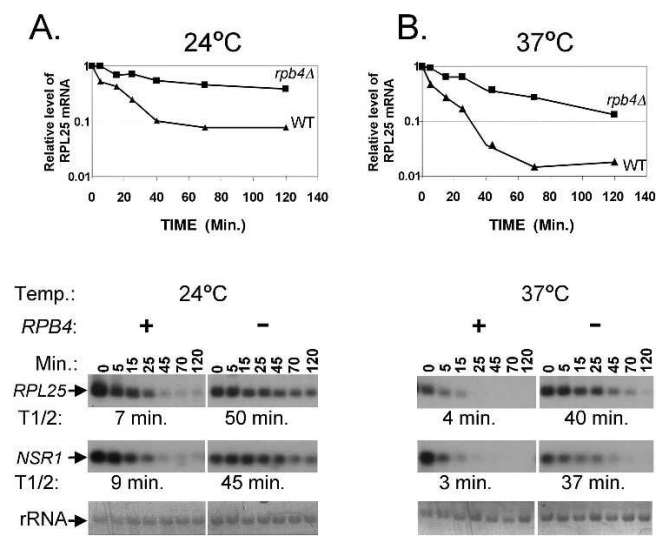

Figure 1. Rpb4p is required for efficient decay of $R P L 25$ and NSR1 mRNAs at both $24^{\circ} \mathrm{C}$ and $37^{\circ} \mathrm{C}$. Wild-type (WT) strain (SUB62) and its isogenic $r p b 4 \Delta$ derivative (MC11-1) were proliferated at $24^{\circ} \mathrm{C}$ until mid-logarithmic phase. Transcription was then blocked by 1, 10 phenanthroline and the cell culture was then incubated at either $24^{\circ} \mathrm{C}(A)$ or $37^{\circ} \mathrm{C}(B)$. Decay kinetics was then determined by monitoring mRNA levels at the indicated time points post-drug treatment, using Northern analysis (as detailed in Materials and Methods). The filter was reacted sequentially with the probes that are indicated at the left in $A$. rRNA (18S) is shown to demonstrate equal loading. Decreased kinetics of mRNA level was determined by PhosphorImager. Band intensity at time 0 (before adding the drug) was defined as 1 and the intensities at the other time points were calculated relative to time 0 . Results were plotted as a function of time post-drug addition. This analysis was used to determine halflives (designated $\mathrm{T}^{1 / 2}$ ). The upper panels show the results of RPL25 mRNA decay kinetics.

ture of most RP and Ribi-mRNAs (Wang et al. 2002; Grigull et al. 2004). In contrast, in isogenic cells lacking $R P B 4$, degradation of these mRNAs was carried out fiveto sevenfold more slowly. These results indicate that $\mathrm{Rpb} 4 \mathrm{p}$ is required (directly or indirectly) for the degradation of RPL25 and NSR1 mRNAs at $24^{\circ} \mathrm{C}$. When wildtype cells were treated with the drug and then shifted to $37^{\circ} \mathrm{C}$, the half-life of these mRNAs became shorter and degradation was more complete (Fig. 1B). We suspect that enhanced degradation of these mRNAs is a reflection and significant component of the more general response to heat shock (HS), when expression of RP and Ribi genes is repressed rigorously at both transcriptional and mRNA decay levels (Herruer et al. 1988; Eisen et al. 1998; Gasch and Werner-Washburne 2002). In rpb4s cells at $37^{\circ} \mathrm{C}$, degradation of RPL25 and NSR1 mRNAs was considerably slower $(\sim 10$-fold). Thus, we found that the role of $\mathrm{Rpb} 4 \mathrm{p}$ in mRNA degradation is evident at both $24^{\circ} \mathrm{C}$ and $37^{\circ} \mathrm{C}$ (Fig. 1A,B). The observation that $\mathrm{Rpb} 4 \mathrm{p}$ functions at a moderate temperature is unexpected considering that its other roles in transcription and in mRNA transport are apparent only under stress (Choder 2004). Nevertheless, we note that the effect of $R P B 4$ deletion upon mRNA stability is more pronounced at $37^{\circ} \mathrm{C}$ than it is at $24^{\circ} \mathrm{C}$.

We examined also the decay of TIF1 and YEF3 mRNAs, encoding translation factors, and found it to be depen- dent on Rpb4p, like the decay of RPL36A mRNA encoding RP (Fig. 2A). In contrast, little or no differences in the decay kinetics of MFA2, ACT1, and TDH3 mRNAs were observed between wild-type and $r p b 4 \Delta$ cells (Fig. 2A,B). Therefore, we conclude that the Rpb4p role in mRNA decay is not general for all mRNAs. Based on our results and microarray results of other investigators, we argue that $\mathrm{Rpb} 4 \mathrm{p}$ is required for the decay of classes of mRNAs whose products are involved in protein synthesis, designated collectively as PBF (Protein Biosynthetic Factors) (see Discussion).

During transcription, Rpb4p functions within the context of Rpb4/7. We have reported previously that Rpb7p interacts with pol II and can function in transcription independently of Rpb4p (Sheffer et al. 1999). Thus, although Rpb4p enhances substantially the interaction of pol II with Rpb7p, the absence of RPB4 can be overcome by overexpressing $R P B 7$. Indeed, the temperature sensitivity of $r p b 4 \Delta$ cells can be suppressed partially by $R P B 7$ overexpression, whereby transcription is recovered partially during temperature stress (especially during mild temperature stress) (see also Fig. 4, below; Sheffer et al. 1999; Tan et al. 2000). To examine whether there is a similar functional relationship between $\mathrm{Rpb} 4 \mathrm{p}$ and $\mathrm{Rpb} 7 \mathrm{p}$ in mRNA decay, we overexpressed RPB7 in $r p b 4 \Delta$ cells and followed the decay rate of several mRNAs. As expected, overexpression of $R P B 7$ in rpb4 cells enhanced transcription of RPL25 and also, slightly, RPL28 prior to the drug addition (Fig. 3, cf. lanes 15 and 8; Sheffer et al. 1999). Surprisingly, overexpression of $R P B 7 \mathrm{did}$ not improve the defective degradation kinetics of RPL25 and RPL28 mRNAs (Fig. 3) or YEF3 and RPL36A mRNAs (results not shown) in these mutant cells. As expected, overexpression of $R P B 7$ also had no effect on the degradation kinetics of MFA2, ACT1, and TDH3 mRNAs (re-

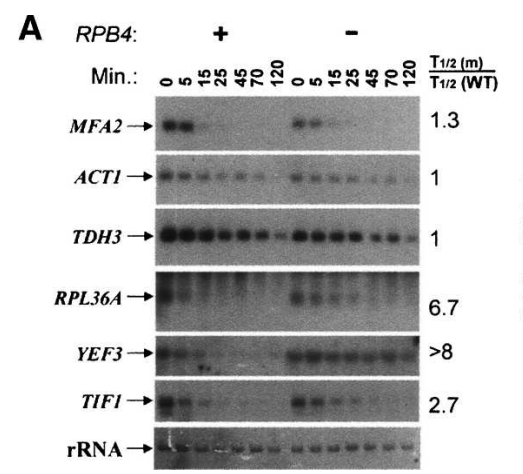

B

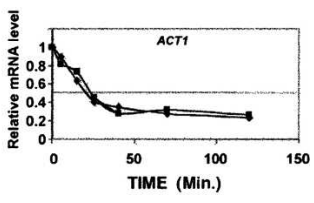

Figure 2. Rpb4p's role in the mRNA decay pathway is specific. (A) Degradation kinetics was determined in wild-type (WT) and $r p b 4 \Delta$ strains as in Figure $1\left(37^{\circ} \mathrm{C}\right)$. The filter was hybridized sequentially to the indicated probes. Half-lives were determined as in Figure 1, and the ratios between $\mathrm{T}^{1} / 2$ of the mutant and that of the wild-type $\left[\mathrm{T}^{1 / 2}(\mathrm{~m}) / \mathrm{T}^{1 / 2}(\mathrm{WT})\right]$ are indicated on the right. rRNA (18S) is shown to demonstrate equal loading. Note that the identical decay kinetics of MFA2, ACT1, and TDH3 mRNAs can serve also as an internal control for equal loading. (B) Decay kinetics of ACT1 mRNA in the wild-type (diamonds)and in $r p b 4 \Delta$ (squares) were determined as in Figure 1. 


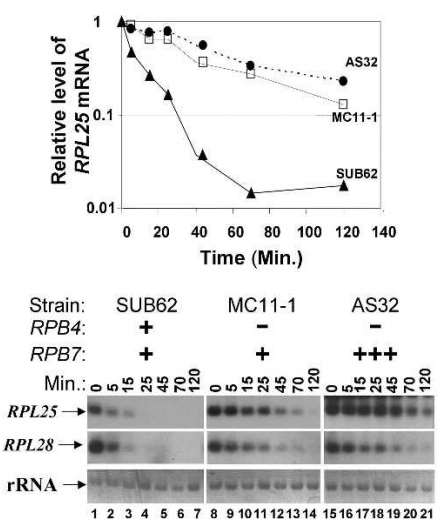

Figure 3. Overexpression of $R P B 7$ does not change the defective decay kinetics of RPL25 and RPL28 mRNAs in $r p b 4 \Delta$ cells. Degradation kinetics in three isogenic strains (see Materials and Methods) was determined as in Figure 1. The absence of a gene $(-)$, the presence of one copy of a gene $(+)$, and the overexpression of a gene $(+++)$ are indicated.

sults not shown). Thus, unlike its function in transcription, the activity of Rpb4p in mRNA degradation is not merely to facilitate $\mathrm{Rpb} 7 \mathrm{p}$ function. These results, however, do not rule out the possibility that $\mathrm{Rpb} 7 \mathrm{p}$ is involved in mRNA decay.

We demonstrated the involvement of Rpb4p in mRNA degradation by another method that does not involve drugs. We took advantage of the normal transcriptional repression of RP genes that occurs in response to HS (Herruer et al. 1988; Eisen et al. 1998; Gasch and WernerWashburne 2002). Indeed, 20 min after shifting the temperature of wild-type cells to $39^{\circ} \mathrm{C}$, the $R P L 25$ and $R P S 8 B$ mRNAs became barely detectable due to both transcriptional repression of RPL25 and RPS $8 B$ and rapid degradation of their mRNAs (Fig. 4, cf. lanes 2 and 1). At later times during $\mathrm{HS}$, transcription of RPL25 and RPS8B resumed (Herruer et al. 1988; Eisen et al. 1998; Warner 1999|, and we observed that the levels of their mRNAs returned to their prior HS levels (Fig. 4, lane 3). In contrast, in rpb4D cells the levels of RPL25 and RPS8B mRNAs decreased only marginally after $20 \mathrm{~min}$ of HS (Fig. 4, cf. lanes 4 and 5), in spite of the robust transcription block that has been demonstrated to occur in these cells in response to HS (Choder and Young 1993; Rosenheck and Choder 1998; Sheffer et al. 1999; Miyao et al. 2001; Pillai et al. 2003). In rpb4s cells, there is no resumption of transcription after HS due to the lack of $\mathrm{Rpb} 4 \mathrm{p}$. Since we did observe a late decrease in the levels of RPL25 and RPS8B mRNAs 100 min after shifting up temperature (Fig. 4, lane 6), we can infer that transcriptional inhibition of these genes was in fact occurring, it was just not visible earlier due to the stability of RPL25 and RPS $8 B$ mRNAs. These aberrant mRNA decay kinetics due to the absence of $\mathrm{Rpb} 4 \mathrm{p}$ are similar to those observed using our other experimental method (Figs. 1-3). $A C T 1$ and RPB7, whose transcripts are shown in Figure 4 , served as non-PBF controls whose transcription in the wild type is little affected by this HS, and their mRNAs are either relatively stable (ACT1) or unstable (RPB7) (Wang et al. 2002; Grigull et al. 2004). Also, monitoring the level of the unstable $R P B 7$ mRNA is useful, as its reduction at $20 \mathrm{~min}$ after temperature shift demonstrates that transcription in $r p b 4 \Delta$ strains was indeed blocked during HS at this time (Fig. 4, cf. lanes 4 and 5 or 7 and 8). Overexpression of $R P B 7$ did not enhance the slow decay kinetics of RPL25 and RPS8B mRNAs (Fig. 4, lanes 7,8), consistent with the results discussed earlier (Fig. 3). Note that overexpressing $R P B 7$ partially suppressed the transcriptional defect of $r p b 4 \Delta$ cells, as previously reported (Maillet et al. 1999; Sheffer et al. 1999; Tan et al. 2000). This can be observed at a later time during the HS when transcription of RP genes is expected to resume (Fig. 4, cf. lanes 9 and 6). Figure 4 demonstrates that $\mathrm{Rpb} 4 \mathrm{p}$ is required for the rapid degradation of $R P L 25$ and RPS $8 B$ mRNAs that occurs naturally during HS, consistent with the results obtained after blocking transcription using a chemical (Figs. 1-3).

$R p b 4$ is required for efficient execution of the deadenylation and post-deadenylation steps that mediate the decay of PBF MRNAs

To examine what steps in PBF mRNAs turnover are stimulated by Rpb4p, we compared the deadenylation kinetics in the wild type with that in $r p b 4 \Delta$ cells. To examine the deadenylation kinetics, we blocked transcription of nonstress genes by shifting cells to heat shock (see Fig. 4) and analyzed the RNA, purified at various time points thereafter, by polyacrylamide electrophoresis Northern technique (Sachs and Davis 1989). We chose to analyze RPL29 mRNA (Fig. 5A) because it is among the shortest PBF mRNAs ( 320-380 bases long) so that differences in its poly(A) tail can easily be detected in this gel system. Three distinct observations can

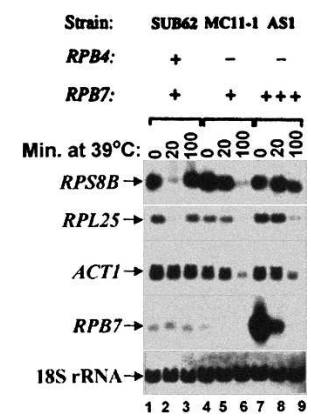

Figure 4. Rpb4p's role in mRNA decay is displayed after exposing cells to heat shock. Cells of the indicated strains (see Materials and Methods) were allowed to proliferate in galactosecontaining medium (to permit overexpression of $\mathrm{p} G A L 1 \mathrm{p}$ $R P B 7)$ at $24^{\circ} \mathrm{C}$ until mid-logarithmic phase. Cell aliquots were taken for time 0 and then the cultures were shifted to $39^{\circ} \mathrm{C}$. Cell samples were harvested at the indicated time points after the shift. Northern analysis was done as in Figure 1. The absence of a gene $(-)$, the presence of one copy of a gene $(+)$, and the overexpression of a gene $(+++)$ are indicated. 


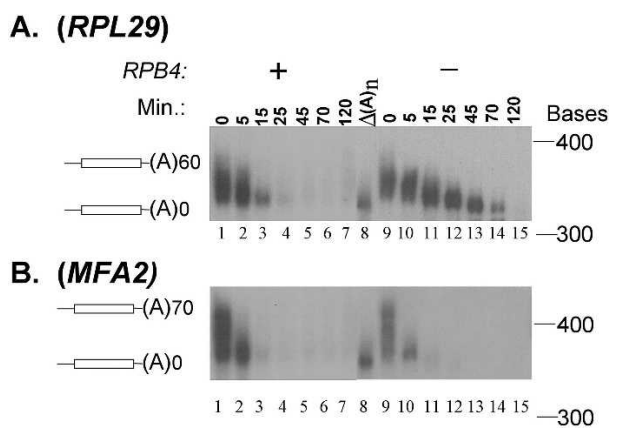

Figure 5. Rpb4p is required for efficient deadenylation and subsequent decay of RPL29 mRNA, but not of MFA2 mRNA. Cells of the indicated strains were allowed to proliferate at $24^{\circ} \mathrm{C}$ until mid-logarithmic phase. Cell aliquots were taken for time 0 and then the culture was shifted rapidly to $42^{\circ} \mathrm{C}$ to arrest transcription of PBF genes. $(A)$ Cell samples were harvested at the indicated time points after the shift and their RNA were analyzed by the polyacylamide Northern technique (see Materials and Methods) and probed first with RPL29. (B) The membrane was then stripped off the first probe and hybridized with MFA2 probe. Lane " $\Delta(\mathrm{A})_{\mathrm{n}}$ " shows the position of fully deadenylated RNA. This RNA was obtained by hybridizing the RNA sample of time point 0 with oligo(dT) followed by digestion of the poly(A) tail by RNase H. Positions of single-stranded DNA size marker are indicated at the right.

be made from the data shown in Figure 5A. First, the decay kinetics of RPL29 mRNA is fast in the wild-type cells and slow in the mutant cells. Second, the deadenylation kinetics is fast in the wild-type and slow in the mutant cells. Specifically, following transcription shutoff, the poly(A) of the RPL29 mRNA was degraded rapidly in the wild-type cells, and complete deadenylation was observed by $15 \mathrm{~min}$ (Fig. 5A, lane 3). In contrast, the deadenylation kinetics in the mutant cells was relatively slow, as complete deadenylation was observed only by $45 \mathrm{~min}$ (Fig. $5 \mathrm{~A}$, lane 13). We conclude that Rpb4p is involved in the rapid deadenylation of RPL29 mRNA. Similar results were observed when RPL25 was probed (results not shown).

The third important observation is that following the deadenylation step, the decay kinetics in the mutant cells was slower than it was in the wild-type cells. Specifically, in the wild-type cells, RPL29 mRNA was completely degraded within $10 \mathrm{~min}$ after its complete deadenylation (Fig. 5A, cf. lanes 4 and 3). In contrast, in the mutant, even 25 min were not sufficient to degrade all the deadenylated mRNAs (Fig. 5A, cf. lanes 14 and 13). For comparison, we note that $25 \mathrm{~min}$ were sufficient for the wild-type cell to both deadenylate and degrade all RPL29 mRNA molecules (Fig. 5, lanes 1-4). Similar results were observed when RPL25 was probed (results not shown). We conclude that Rpb4p is required for efficient degradation of RPL29 mRNA after the deadenylation step.

Interestingly, similar results were obtained when the wild-type cells were compared with cells that carry rpb4-26. This allele of RPB4 carries a single mutation, L180P. Its product was originally identified as one that is defective in supporting transcription (Farago et al. 2003). We now discovered that this mutant is also defective in supporting efficient deadenylation and decay of PBF mRNAs (see Supplementary Fig. S1).

In contrast with the decay pattern of the PBF mRNA, RPL29 mRNA, the decay pattern of a non-PBF mRNA, MFA2 mRNA, is similar in both wild-type and $r p b 4 \Delta$ cells (Fig. 5B). Thus, both the deadenylation and the decay rates are similar in both strains. We conclude that Rpb4 is not involved in the decay pathway of MFA2 mRNA, consistent with the Northern results shown in Figure 2.

Taken together, Rpb4 seems to carry a dual function in the decay of RPL29 and RPL25 mRNAs, one in accelerating deadenylation, and one in a post-deadenylation step-most likely decapping (see Discussion). Consequently, the decay kinetics of these mRNAs in cells carrying either a deletion of $R P B 4$ (Fig. 5) or a mutation in RPB4 (Supplementary Fig. S1) is substantially slower than it is in the wild-type cells.

\section{$\mathrm{Rpb} 4 \Delta$ cells are not defective in nonsense-mediated decay}

Most mRNAs in Saccharomyces cerevisiae do not contain introns. RP mRNAs, whose decay is dependent on $\mathrm{Rpb} 4 \mathrm{p}$, are exceptional in this regard. In most cases the introns are spliced out of the RP mRNAs. However, in some cases, inefficient splicing introduces deleterious pretermination codons. These unspliced mRNAs are recognized and destroyed by the nonsense-mediated decay (NMD) machinery (Wilusz et al. 2001). A known NMD substrate is the RPL28 (known also as CYH2) premRNA, which is inefficiently spliced and its intron contains a stop codon upstream of the major one. This pretermination stop codon is recognized by the NMD machinery (He et al. 1993; Kshirsagar and Parker 2004). Since we report here a novel role for $\mathrm{Rpb} 4 \mathrm{p}$ in the decay of intron-containing RP mRNAs, including RPL28 mRNA (Fig. 3), we asked if it also plays a role in NMD. To determine if Rpb4p affects NMD, the levels of the $R P L 28$ pre-mRNA in $r p b 4 \Delta$ and wild-type strains were analyzed. Examination of RPL28 mRNA at steady state reveals that deletion of $R P B 4$ does not lead to increased levels of pre-RPL28 mRNA (Fig. 6). These results suggest that $\mathrm{Rpb} 4 \mathrm{p}$ does not play a significant role in NMD.

$R p b 4 p$ is localized to the P bodies together with mRNA degradation factors Lsm $1 p$ and Dcp2p and is involved in $P$ bodies function

The novel roles of Rpb4p in mRNA decay together with the previous reports that $\mathrm{Rpb} 4 \mathrm{p}$ is found both in the nucleus and in the cytoplasm (Farago et al. 2003; Choder 2004) provoked us to examine whether Rpb4p is localized to $\mathrm{P}$ bodies. To this end, we have utilized a plasmid expressing GFP-Rpb4p fusion protein whose Rpb4p moiety is fully functional (Farago et al. 2003). Wild-type cells expressing this plasmid, in lieu of $R P B 4$, displayed dis- 


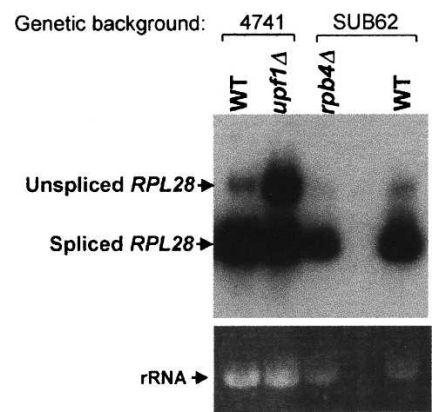

Figure 6. Rpb4p is not essential for NMD. Two iogenic pairs were harvested in mid-logarithmic growth phase and the steadystate levels of their RPL28 (CHY2) mRNAs were analyzed by Northern anaylsis as in Figure 1. The probe was specific for both the intron and the coding region of RPL28, spanning positions 24-730 from ATG in the genomic sequence. Marked by arrows are the positions of RPL28 pre-mRNA (unspliced) and the mature (spliced) mRNA in upf1 $1 \Delta$ and its isogenic wild-type (WT) strain (4741) (left lanes) and $r p b 4 \Delta$ and its isogenic wild-type strain (SUB62) (right lanes). The lane second from the right is empty. EtBr stained 18S rRNA is shown at the bottom to demonstrate that each isogenic pair was loaded equally.

crete foci of GFP-Rpb4p. These foci were observed very rarely $(<1 \%)$ in optimally proliferating cells. To determine if these foci represent $\mathrm{P}$ bodies, we transformed these cells with red fluorescence protein (RFP)-tagged LSM1 or RFP-tagged DCP2, whose product are constituents of P bodies (Sheth and Parker 2003; Kshirsagar and Parker 2004; Teixeira et al. 2005). GFP-Rpb4p foci were colocalized with Dcp2p-RFP foci, thus representing genuine P bodies (Fig. 7A, "Optimal conditions"). Since $\mathrm{P}$ bodies are better detected during starvation (see Discussion), we challenged the cells with starvation. In response to starvation, more GFP-Rpb4 $p$ was found in the cytoplasm, as reported previously (Farago et al. 2003), and the number of GFP-Rpb4p containing $\mathrm{P}$ bodies increased gradually (Fig. 7A, middle and lower panels). Nevertheless, GFP-Rpb4p foci were still observed only in a small fraction of the $\mathrm{P}$ bodies, even under starvation (e.g., see Fig. 7A, middle panels), explaining why similar foci were not observed previously (Farago et al. 2003). We suspected that $\mathrm{Rpb} 4 \mathrm{p}$-containing $\mathrm{P}$ bodies are shortlived, as PBF mRNA are short-lived, and can hardly be detected in wild-type cells (see Discussion).

To slow down the decay of the PBF mRNAs and overcome the poor visibility of Rpb4p-containing $\mathrm{P}$ bodies, we utilized a mutant form of GFP-Rpb4p, GFP-Rpb426p, that we have created previously (Farago et al. 2003). Cells carrying GFP-Rpb4-26p were found to be defective in deadenylation-dependent decay of PBF mRNAs, almost like $r p b 4 \Delta$ cells (Supplementary Fig. S1). Unlike GFP-Rpb4p, GFP-Rpb4-26p-containing P bodies were better visible and were found in high proportion of starved cells (Fig. 7B). Thus, both GFP-Rpb4p and GFPRpb4-26p are localized within P bodies, yet the latter can be detected more easily.

Previously results from Parker's group have indicated that disruption of some P bodies' components increase the number of visible P bodies per cell (Sheth and Parker 2003; Kshirsagar and Parker 2004; see Discussion). Figure $7 \mathrm{C}$ shows that, like disruption of other $\mathrm{P}$ bodies components, deletion of RPB4 increased $\mathrm{P}$ bodies' number. Likewise, the number of $\mathrm{P}$ bodies per cell was higher in cells carrying GFP-rpb4-26 in place of RPB4 than their number in wild-type cells (e.g., Fig. 7, cf. A [middle panels] and B). These results are consistent with the localization of Rpb4p in P bodies and suggest that Rpb4p is involved in $\mathrm{P}$ bodies' function.

It was previously shown that trapping mRNAs in polysomes using the translation inhibitor cycloheximide inhibits the recruitment of mRNAs to $\mathrm{P}$ bodies, thus leading to loss of preexisting $\mathrm{P}$ bodies (Sheth and Parker 2003; Kshirsagar and Parker 2004). GFP-Rpb4-26p foci responded like $\mathrm{P}$ bodies to cycloheximide treatment and disappeared rapidly following drug administration (Fig. 7D). Together, our localization data shown in Figure 7 suggest a direct role for Rpb4p in the decay of specific mRNAs as well as in P bodies' function.

\section{Rpb4p interacts with a component of the mRNP export complex and with Pat1p and with Lsm2p}

As reported above, Rpb4p and Patlp form two-hybrid interaction (see first section of the Results). To further study the mechanism underlying Rpb4p function in the decay pathway of PBF mRNAs, we first determined if this two-hybrid interaction represents an in vivo physical interaction. We have utilized the tandem affinity purification (TAP) technique (Gavin et al. 2002) to immunoprecipitate the TAP-tagged Rpb4p. Patlp was pulled down together with the tagged $\mathrm{Rpb} 4 \mathrm{p}$, demonstrating that the two proteins are components of the same cellular complex (Fig. 8A, lane 4). Note that results of a densitometric scanning indicated that $\sim 85 \%$ of the Pat $1 \mathrm{p}$ molecules were not pulled down by Rpb4-TAP (Fig. 8A, lanes 1,2 ), indicating that $\mathrm{Rpb} 4 \mathrm{p}$ is associated with only a small portion of Patlp $(\sim 15 \%)$. It is quite possible that Pat $1 \mathrm{p}$, like $\mathrm{Rpb} 4 \mathrm{p}$, is associated with various complexes and only a small portion of them share both Rpb4p and Pat1p. We next determined whether RNA is a constituent of this complex by treating cellular extract with RNase A prior to the immunoprecipitation (IP) experiment. RNase A digestion weakened the Rpb4p-Patlp interaction; nevertheless, it did not abolish it completely (Fig. 8A, cf. lanes 4 and 5). The partial dependency of the Rpb4p-Pat1p interaction on RNA suggests that both partners interact directly, while the RNA enhances the interaction. It is possible that RNA binding by either Rpb4p or Pat1p enhances the protein's ability to form a complex with one another.

We have previously proposed that the capacity of $\mathrm{Rpb} 4 \mathrm{p}$ to promote mRNA export involves its ability to interact with mRNA in the nucleus (Farago et al. 2003). Npl3p is a known nuclear RNA-binding factor that is recruited onto transcripts cotranscriptionally and is required for mRNA export (Lei et al. 2001). To determine whether Rpb4p interacts with exported mRNA, we examined if Rpb4p-containing complexes include Npl3p. 
Lotan et al.
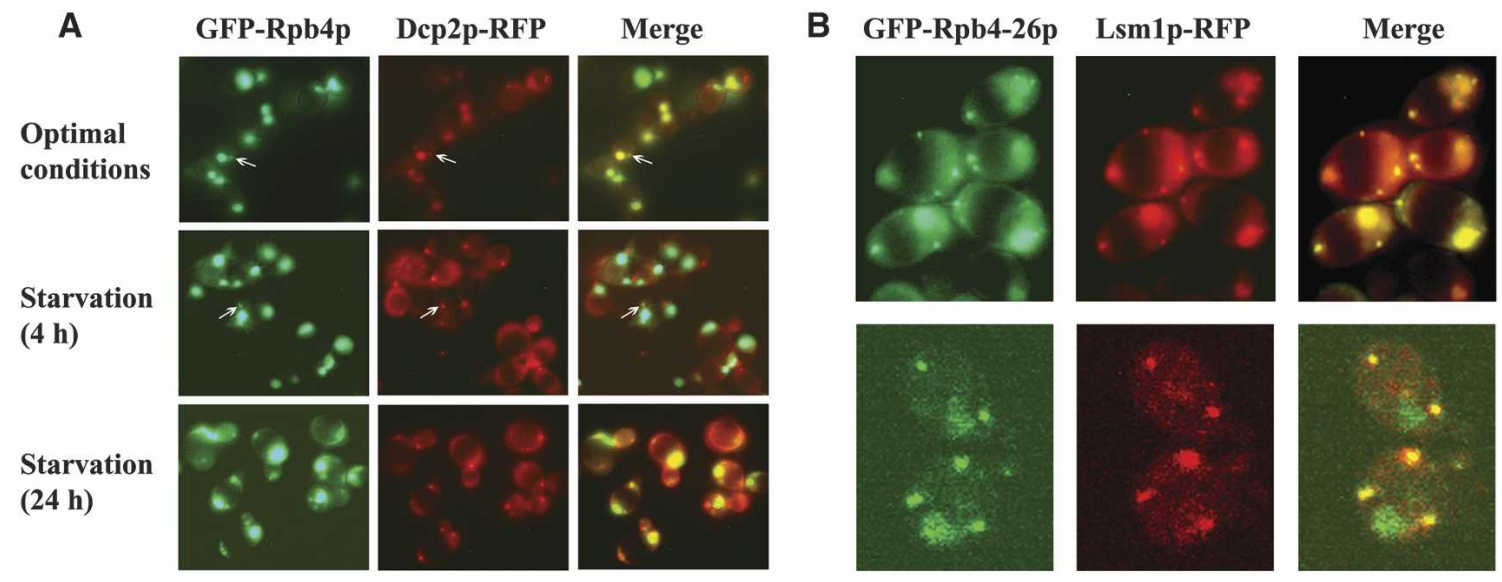

\section{C}
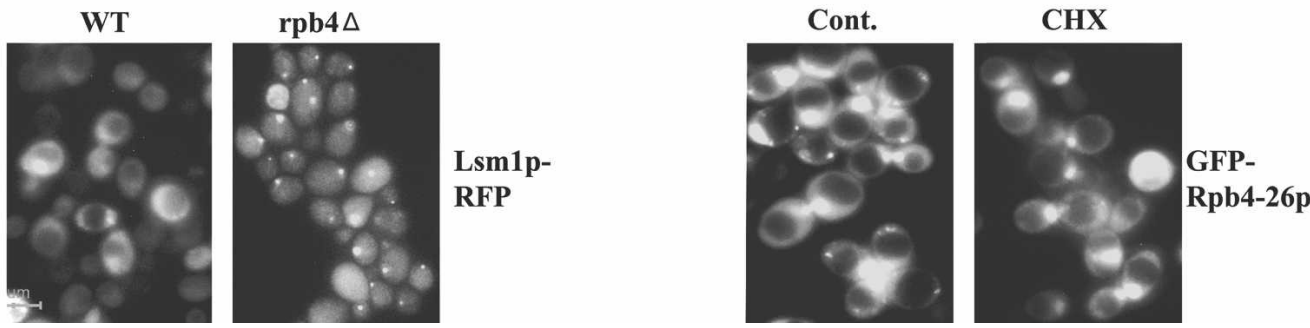

Figure 7. $\mathrm{Rpb} 4 \mathrm{p}$ is colocalized to $\mathrm{P}$ bodies and affects the $\mathrm{P}$ bodies' function. $(A)$ Colocalization of Rpb4p with the $\mathrm{P}$ bodies' marker. Cells expressing the indicated tagged proteins were allowed to proliferate in selective medium at $24^{\circ} \mathrm{C}$. (Upper panels) Cells in mid-log phase were visualized by fluorescent microscopy at either the green (left) or the red (middle) channel. The right panels show the merge generated by Adobe Photoshop. Cells were then shifted to starvation medium lacking any sugar and lacking amino acids for $4 \mathrm{~h}$ (middle panels) or $24 \mathrm{~h}$ (lower panels). Arrows in the upper panels point at some GFP-Rpb4p containing foci, found rarely in optimally growing cells or after $4 \mathrm{~h}$ of starvation. $(B)$ Colocalization of Rpb4-26p with the P bodies' markers. Cells expressing GFP-rpb4-26p, in lieu of RPB4, and Lsm1p-RFP were allowed to proliferate until mid-log followed by $4 \mathrm{~h}$ starvation period, as in the middle panels in $A$. Cells were visualized by fluorescence microscopy (upper panels) or by confocal microscopy (bottom panels). It is worth noting that Rpb4-26-RFP, like GFP-Rpb4-26p, was localized in discrete foci (results not shown), indicating that this type of localization is not a GFP-specific artifact. (C) RPB4 affects the P bodies' number. Wild-type (WT) cells (YMC274) and their isogenic rpb4D derivatives (YCM275), both expressing LSM1-RFP, were allowed to proliferate in a selective medium until early stationary phase (24 h post-diauxic shift), before they were visualized by fluorescent microscopy to detect Lsm1p-RFP-containing P bodies. (D) Effect of cycloheximide on GFP-Rpb4-containing foci. Cells expressing GFP-rpb4-26, in lieu of $R P B 4$, were allowed to proliferate in synthetic medium at $24^{\circ} \mathrm{C}$. When the culture approached mid-log, it was divided into two samples: one treated with $100 \mu \mathrm{M}$ cycloheximide (CHX) and the other with the drug vehicle (ethanol) (Cont.). Cells were incubated with the drug for $15 \mathrm{~min}$ at $24^{\circ} \mathrm{C}$ and then shifted to the starvation medium lacking a carbon source and amino acids, which included the drug or the drug vehicle. GFP-Rpb4-26p localization was determined $4 \mathrm{~h}$ later.

Indeed, we found that Rpb4p interacts with $\mathrm{Npl3p}$ in an RNase A sensitive manner, indicating that both proteins are constituents of the same RNP complex (Fig. 8A, lanes 4,5 ). It is likely that Rpb4p interacts with mRNA either directly or via another factor at some stage during mRNA synthesis or export, thus supporting its export (Farago et al. 2003). Results shown in Figure 8A provide the first in vivo indication that $\mathrm{Rpb} 4 \mathrm{p}$ is a constituent of RNP.

Additional support for a physical interaction between Rpb4p and Patlp was obtained by genetic means, taking advantage of the temperature sensitivity of pat $1 \Delta$ cells (Bonnerot et al. 2000). Indeed, pat1s cells exhibited a growth defect at $36^{\circ} \mathrm{C}$; however, expression of a high- copy plasmid carrying RPB4 suppressed this growthdefect (Fig. 8B). This genetic interaction supports our premise that Rpb4p and Pat1p share similar function(s). The physical and genetic interactions of these partners further reinforce the view that Rpb4p plays a direct role in mRNA decay.

To examine if Rpb4p interacts with mRNA decay factors other than Pat1p, we carried out two-hybrid interactions between RPB 4 as the bait and, as prey, each of 20 genes whose products are known to be involved in the mRNA decay pathway. Out of these 20 genes (listed in the legend to Fig. 8C) only PAT1 and LSM2 showed strong and reproducible interaction with $R P B 4$ (Fig. 8C). We propose that $\mathrm{Rpb} 4 \mathrm{p}$ recruits Patlp to PBF mRNAs 

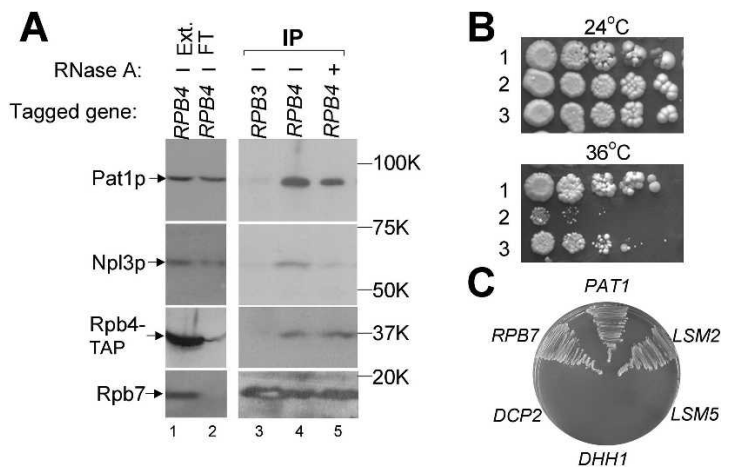

Figure 8. RPB4 interacts with PAT1 and LSM2. (A) Physical interactions. $(B)$ Genetic interactions. $(C)$ Two-hybrid interactions. (A) Coimmunoprecipitation of Rpb4 that was tagged with "tandem affinity purification" (TAP) (Gavin et al. 2002) (designated Rpb4-TAP) and Patlp and Npl3p in the presence or absence of RNase A. Nucleoproteins were extracted from the strain expressing either RPB3-TAP (as the control) or RPB4-TAP under conditions that maintained intact RNAs (see Materials and Methods). Immunoprecipitation with IgG sepharose was done from the indicated extracts with or without prior RNase A treatment (indicated above the lanes), and the various proteins present in the extract (designated Ext) or in the flow-through sample (designated FT) or in the immunoprecipitates were revealed by Western analysis as described in Materials and Methods. Rpb4-TAP (Rpb4-TAP shown in lanes 1,2, or its product released from the column by TEV protease digestion [Gavin et al. 2002], shown in lanes 4,5) was detected by anti-TAP antibodies (Open biosystem). These antibodies detected the Rpb3CBD in lane 1 (not shown). Rpb7p that is coimmunoprecipitated with both Rpb4-TAP and Rpb3-TAP is shown to demonstrate equal immunoprecipitation efficiencies. $(B)$ High copy suppression of pat1 $\Delta$ defect by RPB4. Isogenic strains wild-type (lane 1),

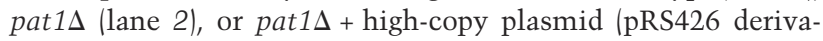
tive) expressing RPB4 (lane 3) were spotted onto two plates in fivefold serial dilutions. Cells were allowed to grow at either $24^{\circ} \mathrm{C}$ or $36^{\circ} \mathrm{C}$, as indicated. (C) Two-hybrid interactions between RPB4 as the bait and genes whose products are involved in mRNA decay as prey have been performed as described in Materials and Methods. Only five of 20 genes tested are shown as indicated around the plate. The other genes that did not exhibit interactions with the RPB4-DBD and are not shown here are LSM1, LSM4-LSM7, CCR4, NOT1, CAF1, PAN3, PAN2, $P O P 2, E D C 1, E D C 2, E D C 3, P A B 1$. Equal amount of cells, carrying the indicated prey plasmids, were streaked onto an indicator plate as described in Materials and Methods. We then verified that the growth on the indicator plates was dependent on both plasmids by evicting one plasmid at a time from each of the positive clones (results not shown). Units of $\beta$-gal, a third reporter of the two-hybrid interaction, were also determined by liquid tests and yielded results that were consistent with the growth phenotype (data not shown).

and also stabilizes the association of the Pat1/Lsm1-7 complex with these mRNAs, by virtue of its capacity to interact both with the mRNAs, with Patlp, and with Lsm2p.

The high copy suppression observed in Figure 8B suggests that Rpb4p can recruit Lsm1-7 complex independently of Pat1p, possibly through its interaction with Lsm2p. This possibility predicts that overexpression of $R P B 4$ would suppress partially the defective decay of PBF
mRNAs that characterize pat1 $1 \Delta$ cells. To examine this possibility, we determined the decay kinetics of RPL29 in pat $1 \triangle$ cells and found no apparent effect of RPB4 overexpression (Supplementary Fig. S2). This result suggests that Pat 1 is essential for the capacity of Rpb4p to recruit the Pat1/Lsm1-7 complex. The mechanism underlying the capacity of the overexpressed RPB4 to partially suppress the growth defect of pat $1 \Delta$ cells remains to be determined.

\section{Discussion}

A novel role for $R p b 4 p$ in the decay pathway of mRNAs in the cytoplasm

We have discovered two novel roles for Rpb4p in the decay pathway of specific classes of mRNAs. Effect of Rpb4 on mRNA half lives was determined by two independent assays, one involving a drug and one that involves no drug. We have thus found the Rpb4p is required for efficient deadenylation of PBF mRNAs and most likely also for their efficient decapping. Not only is $\mathrm{Rpb} 4$ required for the normal deadenylation-dependent decay of these mRNAs, it is also a constituent of the $\mathrm{P}$ bodies. Moreover, defects in $\mathrm{Rpb} 4 \mathrm{p}$ increase the number of $\mathrm{P}$ bodies, much like defects in other known mRNA decay factors (Sheth and Parker 2003; Kshirsagar and Parker 2004). In additions, Rpb4 interacts both physically and genetically with components of the Pat1/ Lsm 1-7 complex. Taken together, these observations indicate a direct role of Rpb4p in the decay of PBF mRNAs. As $\mathrm{Rpb} 4 \mathrm{p}$ is required for mRNA transport (Farago et al. 2003), it might be possible that cells lacking RPB4 fail to degrade mRNAs because they are retained in their nuclei. However, we argue that Rpb4p is involved expressly in the cytoplasmic decay pathway for the following reasons. First, $r p b 4 \Delta$ cells are not defective in transport under optimal proliferation conditions at mild temperatures (Farago et al. 2003), yet under these conditions they are defective in mRNA degradation (e.g., Fig. 1A). Second, $\mathrm{Rpb} 4 \mathrm{p}$ is involved in the deadenylation-dependent decay pathway that is carried out in the cytoplasm (Coller and Parker 2004). Third, Rpb4p is found in the cytoplasmic P bodies, where mRNA decapping and its deg-

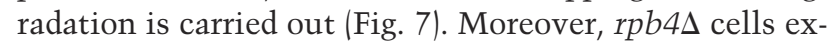
hibit abnormally high levels of $\mathrm{P}$ bodies, indicative of defective cytoplasmic degradation. Fourth, the interaction of Rpb4p with Patlp that is involved in the cytoplasmic decay pathway (Coller and Parker 2004) is consistent with a role for Rpb4p in the cytoplasmic pathway.

\section{$R p b 4 p$ is required specifically for decay of $m R N A s$ encoding protein biosynthetic factors}

In light of our results, we propose that the involvement of $\mathrm{Rpb} 4 \mathrm{p}$ in mRNA decay is specific to classes of mRNAs that encode functionally related proteins. We have found that the normal decay kinetics of several classes of mRNAs is dependent on Rpb4: (1) mRNAs encoding RP—RPL25 mRNA (Figs. 1, 3, 4; Supplementary Fig. S1), 
RPL36A mRNA (Fig. 2), RPS8B mRNA (Fig. 4), RPL28 (CYH2) mRNA (Figs. 3, 6), and RPL29 (Fig. 5; Supplementary Fig, S1); (2) mRNA encoding a Ribi proteinNSR1 mRNA (Fig. 1); and (3) mRNAs encoding translation factors-TIF1 mRNAs (Fig. 2) and YEF3 (Fig. 2; Supplementary Fig. S1).

A whole genome analysis from Sadhale's group has revealed previously that, after $30 \mathrm{~min}$ of HS, the levels of the vast majority of the mRNAs are lower in $r p b 4 \Delta$ cells than they are in the wild-type cells (Pillai et al. 2003). These results are consistent with a general role of Rpb4 in transcription during HS. Unexpectedly, however, the levels of PBF mRNAs were found to be higher in $r p b 4 \Delta$ cells than they are in the wild-type cells (Fig. 4 shows a similar approach in a small scale, with similar results; Pillai et al. 2003). Specifically, the mRNAs affected were those that code for 97 ribosomal proteins, translation initiation factors, aminoacyl tRNA synthetases, and Ribi proteins. These observations were unexpected and noninterpretable at that time, because under HS the transcription in the mutant cells is blocked (Choder 2004). The mRNAs whose decay kinetics we found to be dependent on Rpb4 belong to these classes. We now view the microarray results as being consistent with a role for $\mathrm{Rpb} 4 \mathrm{p}$ in the decay of all these mRNAs, supporting a general role for $\mathrm{Rpb} 4 \mathrm{p}$ in the decay of these specific classes of mRNAs, which we have designated PBF.

\section{A dual role for Rpb4 in the decay of PBF mRNAs}

Our results indicate that $\mathrm{Rpb} 4 \mathrm{p}$ has at least two functions in the decay of PBF mRNAs. It promotes or enhances the deadenylation step and it is required for the post-deadenylation step (Fig. 5; Supplementary Fig. S1B). We argue that the second step is decapping based on the observations that Rpb4p interacts and probably recruits the Pat1/Lsm1-7 complex that stimulates decapping and it is localized in P bodies, where decapping is carried out. Detailed mechanistic understanding of how Rpb4p mediates these two processes remains to be deciphered. It is worth noting that our two-hybrid experiment failed to detect interactions between Rpb4p and most known decay factors except for Patlp and Lsm2p (see Fig. 8C). Although a role for Rpb4p in decapping is very likely, we do not rule out the possibility that the post-deadenylation step involves other activities such as mRNA recruitment to the $\mathrm{P}$ bodies or stimulation of the exonuclease(s) that digest(s) the PBF mRNAs.

The dual role of Rpb4p in mRNA decay indicates that this protein plays a key role in PBF mRNAs turnover by possibly linking the deadenylation and decapping stages. This explains why deletion of $R P B 4$, or even a point mutation in this gene, had such a deleterious effect on the decay kinetics of the PBF mRNAs (Figs. 1-5; Supplementary Fig. S1). Although these two stages are traditionally regarded as distinct processes, as each of them is mediated by different factors, there are reports on factors that participate in both steps. For example, Puf3p is required for the decay of a distinct group of genes at both the deadenylation and decapping levels /Olivas and Parker
2000). Detailed understanding of this possible linking mechanism(s) awaits future studies.

\section{Possible Rpb4p-mediated coupling of transcription and mRNA decay: a cost-effective mechanism to regulate $m R N A$ levels}

$\mathrm{Rpb} 4 \mathrm{p}$ is an integral and essential constituent of pol II (Choder 2004). Our results reveal, for the first time, the involvement of a component of the general transcription apparatus in mRNA decay. As the function of Rpb4p in mRNA decay seems to be specific to PBF mRNAs, it is quite possible that Rpb4p is involved in determining the abundance of these mRNAs both at the level of their synthesis and at the level of their decay (see below). PBF gene expression has unique features. First, expression of these genes is involved in the regulation of cell growth and division (Dez and Tollervey 2004). Second, although these genes constitute a small fraction of the yeast $\sim 6000$ genes, $\sim 50 \%$ of the total pol II transcription complexes are devoted to their transcription (Warner 1999). Consequently, expression of PBF genes imposes a substantial energetic burden on the cells, which can be afforded only under favorable environmental conditions. Therefore, expression of these genes is extremely sensitive to environmental signals (Eisen et al. 1998; Gasch and WernerWashburne 2002; Yin et al. 2003; Garcia-Martinez et al. 2004), and is controlled by various signaling pathways (see Martin et al. 2004 and references therein). Under favorable conditions, these genes are both highly transcribed and their mRNAs have very short half-lives (Warner et al. 2001; Wang et al. 2002; Grigull et al. 2004). This is a costly mechanism for maintaining mRNA levels, but it has the advantageous capacity to respond rapidly to changes in the environment. This costly regulation of expression requires tight coordination between transcription and mRNA decay, as uncontrolled change in one process can have a profound and deleterious effect on mRNA levels. Indeed, as expected, both transcription of PBF genes and the decay of their mRNAs are each regulated in response to environmental conditions. Remarkably, the balance between transcription and mRNA decay appears to vary according to the environmental conditions. For example, in response to HS, the transcription of RP genes is repressed while their degradation is carried out efficiently (see Figs. 1, 4, 5; Supplementary Fig. S1; Herruer et al. 1988; Li et al. 1999; Garcia-Martinez et al. 2004; Grigull et al. 2004). In contrast, in response to glucose deprivation, both the synthesis and decay of RP mRNAs are repressed (Jona et al. 2000; Garcia-Martinez et al. 2004). The former regulatory response leads to a rapid decline in the expression of these genes, whereas the latter preserves precious energy on the one hand while maintaining high levels of mRNAs on the other hand, ready to be utilized when famine is broken (a general strategy for starved yeast) (see discussion in Jona et al. 2000). Considering these and other scenarios, the advantage of having factors that coordinate between transcription of PBF genes and their mRNA decay in response to environmental signals is obvious. 
Since we can demonstrate a requirement for $\mathrm{Rpb} 4 \mathrm{p}$ in degradation of PBF mRNAs, the observation that the steady-state abundance of these mRNAs at moderate temperatures is not higher in $r p b 4 \Delta$ cells than it is in the wild-type cells is surprising (see Figs, 1-5; see also Miyao et al. 2001; Pillai et al. 2003). Other investigators have found also that despite defective mRNA decay in certain mutant strains, steady-state levels of classes of PBF mRNAs are unaltered. For example, the steady-state levels of Ribi mRNAs in some decay mutants, e.g., ccr4, pan2, and puf4, are largely unchanged (Grigull et al. 2004). Grigull et al. suggest that, in these mutants, the synthesis of the Ribi mRNAs is down-regulated to compensate for their increased stability. It seems likely that yeast cells have evolved a feedback mechanism that monitors the levels of the PBF mRNAs and coordinates between transcription and decay mechanisms. In light of these observations and ours, it is quite possible that transcription of PBF genes is down-regulated in $r p b 4 \Delta$ cells, even at moderate temperatures when transcription of other genes is little dependent on Rpb4p. We further propose that Rpb4p is in good cellular and molecular positions to be involved in the putative feedback mechanism that coordinates PBF transcription and mRNA decay. Interestingly, although overexpressing $R P B 7$ does not restore the defective decay of PBF mRNAs in $r p b 4 \Delta$ cells, it does enhance their transcription (Sheffer et al. 1999). It is possible, then, that the $\mathrm{Rpb} 4 / 7$ heterodimer, rather than $\mathrm{Rpb} 4 \mathrm{p}$ alone, is involved in the coordination between transcription of PBF genes and decay of their transcripts. The relatively small effect of $R P B 7$ overexpression on the steady-state level of PBF mRNAs during proliferation at moderate temperatures $(-20 \%)$ suggests that the heterodimer functions within a larger context of regulatory network that together controls PBF mRNAs levels.

Rpb4p functions in transcription and mRNA export are prominent only under stress conditions /Choder 2004); however, the Rpb4p role in mRNA decay is evident under both optimal conditions and stressful conditions (HS) (Fig. 1). Nevertheless, we hypothesize that under optimal growth conditions Rpb4p does not serve as a key coordinator between transcription and decay, since, as discussed above, the steady-state levels of PBF mRNAs are close to normal in $r p b 4 \Delta$ cells (see 0 time points in Figs. 1-5; Pillai et al. 2003). However, during stress, when Rpb4 is essential for viability (Choder 2004), Rpb4p might have a more pivotal role in this putative coordination process, as suggested by the uncontrolled levels of PBF mRNAs in $r p b 4 \Delta$ cells during HS (Figs. 4, 5; Supplementary Fig. S1; Pillai et al. 2003).

\section{Functional implications of the interactions of $R p b 4 p$} with Pat1p

Pat1p, whose biochemical properties are not well understood, is a component of the Pat1/Lsm1-7 complex functions in mRNA decapping and decay (Zhang et al. 1999; Bonnerot et al. 2000; Tharun et al. 2000). Patlp is found associated with mRNAs that carry the translation fac- tors Pablp, eIF4E, and eIF4G (Tharun and Parker 2001), strongly suggesting that it is recruited to the mRNA during or before translation. Pat $1 p$, in turn, probably recruits Lsm1-7 by a mechanism whose regulation is unclear. This recruitment seems to signal a major rearrangement of the mRNP, whereby it changes from one that translates $\mathrm{mRNP}$ into one that no longer carries the above translation factors and is destined for decapping and decay (Tharun and Parker 2001). Prior to this work, it was not known how Patlp is recruited to the mRNA. Being a pol II subunit, Rpb4p probably interacts with the transcripts during transcription in the nucleus (Farago et al. 2003; Choder 2004) and accompanies the transcript during its export to the cytoplasm, together with Npl3p (Fig. 8A), before Patlp assembly. Therefore, the capacity of Rpb4p to interact with both the mRNP and with Patlp suggests that $\mathrm{Rpb} 4 \mathrm{p}$ is involved in recruiting Patlp to PBF mRNAs. We also propose that Rpb4p helps facilitate and stabilize the interaction between Pat1p and Lsm1-7 through its capacity to interact with both Patlp and possibly also Lsm2p. Recruitment of the Pat1/Lsm1-7 complex by Rpb4p is consistent with the role of the latter in the post-deadenylation step and strongly suggests that this step is decapping (see above).

It is worth noting that Pat $1 \mathrm{p}$ is involved in the decay of a non-PBF mRNA, MFA2 mRNA (Bonnerot et al. 2000; Kshirsagar and Parker 2004; Coller and Parker 2005). Because deletion of $R P B 4$ has little effect on the decay kinetics of MFA2 mRNA (Fig. 2), it is unlikely (though not impossible) that Patlp is recruited to non-PBF mRNAs by $\mathrm{Rpb} 4 \mathrm{p}$. The mechanism underlying Patlp recruitment to non-PBF mRNAs remains to be determined.

\section{$R p b 4 p$ is localized in a subpopulation of $P$ bodies and is involved in their function}

Our results clearly show that most Lsm1p-RFP or Dcp2p-RFP containing P bodies do not contain wild-type GFP-Rpb4p (see Fig. 7A; results not shown). These results might have trivial explanations. For example, it is possible that the tag compromises the capacity of the protein to interact with the $\mathrm{P}$ bodies. Consequently, we see only a portion of these bodies using RFP and a different portion of $\mathrm{P}$ bodies using GFP, with some overlaps. However, because GFP-Rpb4-26p that carries the same GFP as does GFP-Rpb4 is localized in a higher proportion of $\mathrm{P}$ bodies (Fig. 7B), we believe this possibility less likely. More likely, it is possible that there are different types of $\mathrm{P}$ bodies, accommodating different classes of mRNAs and different combinations of decay factors. We propose that $\mathrm{Rpb} 4 \mathrm{p}$ resides in $\mathrm{P}$ bodies specialized in degradation of PBF mRNAs, while Lsm1p or Dcp2p reside in all $\mathrm{P}$ bodies. Specialized $\mathrm{P}$ bodies have the potential capacity to spatially coordinate the degradation of classes of mRNAs. Indeed, decay of RP mRNAs is coordinately regulated and they were proposed to constitute a "decay regulon" (see Introduction).

$\mathrm{P}$ bodies are dynamic structures whose size and number can vary according to decay kinetics /Sheth and Parker 2003; Coller and Parker 2004; Teixeira et al. 
2005). Thus, cells that are actively degrading decapped mRNAs, like dividing cells (Fig. 7A), exhibit barely detectable $\mathrm{P}$ bodies. As PBF mRNAs are among the shortest lived mRNAs in yeast (Wang et al. 2002; Grigull et al. 2004), it is likely that $\mathrm{P}$ bodies carrying these mRNAs are small and undetectable. However, in the absence of $R P B 4$ (Fig. 7C) or in the case of $r p b 4$ mutants (Fig. 7B), when the degradation kinetics of PBF mRNAs is slower, it follows that PBF mRNA-containing P bodies are detected readily. Because PBF mRNAs constitute a significant proportion of the total mRNAs, the appearance of this putative class of $\mathrm{P}$ bodies increases the overall number of detectable foci in the cell (Fig. 7B, C).

\section{Materials and methods}

\section{Yeast strains}

The yeast strains used are SUB62, MC11-1, AS1, AS32 (described by Sheffer et al. 1999), YMC274 (MATa, ura3-52, lys2801 [amber], ade2-101 [amber], trp1- $\Delta 1$, his3- $\Delta 200$, leu2- $\Delta 1$ ), and YMC275 (MATa, ura3-52, lys2-801 [amber], ade2-101 [amber], trp1- $\Delta 1$, his3- $\Delta 200$, leu2- $\Delta 1 \operatorname{rpb} 4 \Delta::$ HIS3). Rpb3TAP (MATa; ade2; arg4; leu2-3,112; trp1-289; ura3-52 YIL021w::TAP-K.I URA3) and Rpb4-TAP (MATa; ade2; arg4; leu2-3,112; trp1-289; ura3-52 YJL140W::TAP-K.I URA3) were obtained from Euroscarf.

\section{Determining $m R N A$ degradation profile}

Cell aliquot was taken for time 0 . The culture were then treated with $100 \mu \mathrm{M}$ of 1,10 , phenanthroline (Merk). Cultures were shaken at the indicated temperature while cell aliquots $\left(1 \times 10^{8}\right.$ to $2 \times 10^{8}$ cells) were taken at the indicated time points postdrug administration into $15-\mathrm{mL}$ tubes. Cell aliquots were cooled to $\sim 5^{\circ} \mathrm{C}$ rapidly by placing the tubes in liquid nitrogen with vigorous shaking for $10-15 \mathrm{sec}$. Cells were then rapidly harvested and suspended in the RNA extraction buffer and immediately frozen in liquid nitrogen (Choder 1991). RNA purification and Northern blot hybridization were done as described previously (Choder 1991). Usually $3 \mu$ g of RNA were loaded per lane. Polyacrylamide Northern analysis (Sachs and Davis 1989) was performed using $20 \times 20 \times 0.1 \mathrm{~cm}$ gel of $6 \%$ polyacrylamide, $7 \mathrm{M}$ urea in $1 \times \mathrm{TBE}$ (tris borate, EDTA) buffer. The RNA (usually $2.5 \mu \mathrm{g} / \mathrm{lane}$ ) was then electro-transferred onto GeneScreen plus membrane (Perkin Elmer) in $0.5 \times$ TBE at $30 \mathrm{~V}$ for $12-15 \mathrm{~h}$ at $4^{\circ} \mathrm{C}$. The membrane was probed as described previously (Choder 1991).

\section{Fluorescent and confocal microscopy}

Fluorescent microscopy was done as described previously (Farago et al. 2003).

Confocal microscope Radiance2000 (Bio-Rad) was loaded on a Nikon E600 microscope using Plan Apo $60 \times 1.4$ oil Dic objective.

\section{Two-hybrid assay}

The bait RPB4-AD was constructed as instructed (Uetz et al. 2000). The bait plasmid was introduced by transformation into any of the prey-containing (cloned in pOAD) strains (Uetz et al. 2000) (a generous gift of the Yeast Resource Center, Washington University, funded by NIH grant PHS \#P41 RR11823). Twohybrid interaction was determine by growth on plates lacking leucine, tryptophane, adenine, and histidine supplemented with
$5 \mathrm{mM}$ 3-amino-1,2,4-triazole and by $\beta$-gal liquid test, as reported previously (Uetz et al. 2000).

\section{Immunoprecipitation and Western analysis}

Rpb4 was tagged with tandem affinity purification (TAP) tag (Gavin et al. 2002). RNPs were extracted from exponentially proliferating cells by glass bead disruption of cells in NP40 buffer (Gavin et al. 2002) supplemented with $1 \mathrm{U} / \mu \mathrm{L}$ RNasin (Promega); $0.5 \mathrm{U} / \mu \mathrm{L}$ SUPERase-in (Ambion). RNPs were purified with IgG-sepharose column as described (Gavin et al. 2002). RNase A $(200 \mu \mathrm{g} / \mathrm{mL})$ was added, when indicated, prior the IP and the sample was incubated at $4^{\circ} \mathrm{C}$ for $25 \mathrm{~min}$ to digest the RNA.

\section{Acknowledgments}

We thank Roy Parker and members of his group for critically reading the manuscript and for their advice. We thank Roy Parker for RFP plasmids, Pamela Silver and Francoise Wyers for antibodies, and Edith Suss-Toby for her excellent assistance with the confocal microscope. This work was supported by the Israel Science Foundation founded by the Israel Academy of Sciences and Humanities.

\section{References}

Armache, K.J., Kettenberger, H., and Cramer, P. 2003. Architecture of initiation-competent 12-subunit RNA polymerase II. Proc. Natl. Acad. Sci. 100: 6964-6968.

Badis, G., Saveanu, C., Fromont-Racine, M., and Jacquier, A. 2004. Targeted mRNA degradation by deadenylation-independent decapping. Mol. Cell 15: 5-15.

Bashkirov, V.I., Scherthan, H., Solinger, J.A., Buerstedde, J.M., and Heyer, W.D. 1997. A mouse cytoplasmic exoribonuclease (mXRN1p) with preference for G4 tetraplex substrates. I. Cell. Biol. 136: 761-773.

Bonnerot, C., Boeck, R., and Lapeyre, B. 2000. The two proteins Patlp (Mrtlp) and Spb8p interact in vivo, are required for mRNA decay, and are functionally linked to Pablp. Mol. Cell. Biol. 20: 5939-5946.

Brown, C.E. and Sachs, A.B. 1998. Poly(A) tail length control in Saccharomyces cerevisiae occurs by message-specific deadenylation. Mol. Cell. Biol. 18: 6548-6559.

Bushnell, D.A. and Kornberg, R.D. 2003. Complete, 12-subunit RNA polymerase II at 4.1-A resolution: Implications for the initiation of transcription. Proc. Nat1. Acad. Sci. 100: 69696973.

Choder, M. 1991. A general topoisomerase I-dependent transcriptional repression in the stationary phase in yeast. Genes \& Dev. 5: 2315-2326.

- 2004. Rpb4 and Rpb7: Subunits of RNA polymerase II and beyond. Trends Biochem. Sci. 29: 674-681.

Choder, M. and Young, R.A. 1993. A portion of RNA polymerase II molecules has a component essential for stress responses and stress survival. Mol. Cell. Biol. 13: 6984-6991.

Collart, M.A. 2003. Global control of gene expression in yeast by the Ccr4-Not complex. Gene 313: 1-16.

Coller, J. and Parker, R. 2004. Eukaryotic mRNA decapping. Annu. Rev. Biochem. 73: 861-890.

- 2005. General translational repression by activators of mRNA decapping. Cell 122: 875-886.

Decker, C.J. and Parker, R. 1993. A turnover pathway for both stable and unstable mRNAs in yeast: Evidence for a requirement for deadenylation. Genes \& Dev. 7: 1632-1643. 
Dez, C. and Tollervey, D. 2004. Ribosome synthesis meets the cell cycle. Curr. Opin. Microbiol. 7: 631-637.

Eisen, M.B., Spellman, P.T., Brown, P.O., and Botstein, D. 1998. Cluster analysis and display of genome-wide expression patterns. Proc. Natl. Acad. Sci. 95: 14863-14868.

Farago, M., Nahari, T., Hammel, C., Cole, C.N., and Choder, M. 2003. Rpb4p, a subunit of RNA polymerase II, mediates mRNA export during stress. Mol. Cell. Biol. 14: 2744-2755.

Garcia-Martinez, J., Aranda, A., and Perez-Ortin, J.E. 2004. Genomic run-on evaluates transcription rates for all yeast genes and identifies gene regulatory mechanisms. Mol. Cell 15: 303-313.

Gasch, A.P. and Werner-Washburne, M. 2002. The genomics of yeast responses to environmental stress and starvation. Funct. Integr. Genomics 2: 181-192.

Gavin, A.C., Bosche, M., Krause, R., Grandi, P., Marzioch, M., Bauer, A., Schultz, J., Rick, J.M., Michon, A.M., Cruciat, C.M., et al. 2002. Functional organization of the yeast proteome by systematic analysis of protein complexes. Nature 415: 141-147.

Grigull, J., Mnaimneh, S., Pootoolal, J., Robinson, M.D., and Hughes, T.R. 2004. Genome-wide analysis of mRNA stability using transcription inhibitors and microarrays reveals posttranscriptional control of ribosome biogenesis factors. Mol. Cell. Biol. 24: 5534-5547.

He, F., Peltz, S.W., Donahue, J.L., Rosbash, M., and Jacobson, A. 1993. Stabilization and ribosome association of unspliced pre-mRNAs in a yeast upf1- mutant. Proc. Nat1. Acad. Sci. 90: 7034-7038.

Herruer, M.H., Mager, W.H., Raue, H.A., Vreken, P., Wilms, E., and Planta, R.J. 1988. Mild temperature shock affects transcription of yeast ribosomal protein genes as well as the stability of their mRNAs. Nucleic Acids Res. 16: 7917-7929.

Ingelfinger, D., Arndt-Jovin, D.J., Luhrmann, R., and Achsel, T. 2002. The human LSm1-7 proteins colocalize with the mRNA-degrading enzymes Dcp1/2 and Xrnl in distinct cytoplasmic foci. RNA 8: 1489-1501.

Jack, H.M. and Wabl, M. 1988. Immunoglobulin mRNA stability varies during B lymphocyte differentiation. EMBO $I$. 7: 1041-1046.

Jacobson, A. and Peltz, S.W. 1996. Interrelationships of the pathways of mRNA decay and translation in eukaryotic cells. Annu. Rev. Biochem. 65: 693-739.

Jona, G., Choder, M., and Gileadi, O. 2000. Glucose starvation induces a drastic reduction in the rates of both transcription and degradation of mRNA in yeast. Biochim. Biophys. Acta 1491: $37-48$.

Khazak, V., Sadhale, P.P., Woychik, N.A., Brent, R., and Golemis, E.A. 1995. Human RNA polymerase II subunit hsRPB7 functions in yeast and influences stress survival and cell morphology. Mol. Cell. Biol. 6: 759-775.

Kshirsagar, M. and Parker, R. 2004. Identification of Edc3p as an enhancer of mRNA decapping in Saccharomyces cerevisiae. Genetics 166: 729-739.

Lei, E.P., Krebber, H., and Silver, P.A. 2001. Messenger RNAs are recruited for nuclear export during transcription. Genes \& Dev. 15: 1771-1782.

Li, B., Nierras, C.R., and Warner, J.R. 1999. Transcriptional elements involved in the repression of ribosomal protein synthesis. Mol. Cell. Biol. 19: 5393-5404.

Lykke-Andersen, J. 2002. Identification of a human decapping complex associated with hUpf proteins in nonsense-mediated decay. Mol. Cell. Biol. 22: 8114-8121.

Maillet, I., Buhler, J.M., Sentenac, A., and Labarre, J. 1999. Rpb4p is necessary for RNA polymerase II activity at high temperature. J. Biol. Chem. 274: 22586-22590.
Mangus, D.A., Evans, M.C., and Jacobson, A. 2003. Poly(A)binding proteins: Multifunctional scaffolds for the post-transcriptional control of gene expression. Genome Biol. 4: 223.

Martin, D.E., Soulard, A., and Hall, M.N. 2004. TOR regulates ribosomal protein gene expression via PKA and the Forkhead transcription factor FHL1. Cell 119: 969-979.

McKune, K., Richards, K.L., Edwards, A.M., Young, R.A., and Woychik, N.A. 1993. RPB7, one of two dissociable subunits of yeast RNA polymerase II, is essential for cell viability. Yeast 9: 295-299.

Mitsuzawa, H., Kanda, E., and Ishihama, A. 2003. Rpb7 subunit of RNA polymerase II interacts with an RNA-binding protein involved in processing of transcripts. Nucleic Acids Res. 31: 4696-4701.

Miyao, T., Barnett, J.D., and Woychik, N.A. 2001. Deletion of the RNA polymerase subunit RPB4 acts as a global, not stress-specific, shut-off switch for RNA polymerase II transcription at high temperatures. J. Biol. Chem. 276: 4640846413.

Morris, T.D., Weber, L.A., Hickey, E., Stein, G.S., and Stein, J.L. 1991. Changes in the stability of a human H3 histone mRNA during the HeLa cell cycle. Mol. Cell. Biol. 11: 544-553.

Olivas, W. and Parker, R. 2000. The Puf3 protein is a transcriptspecific regulator of mRNA degradation in yeast. $E M B O J$. 19: 6602-6611.

Parker, R. and Song, H. 2004. The enzymes and control of eukaryotic mRNA turnover. Nat. Struct. Mol. Biol. 11: 121127.

Pillai, B., Verma, J., Abraham, A., Francis, P., Kumar, Y., Tatu, U., Brahmachari, S.K., and Sadhale, P.P. 2003. Whole genome expression profiles of yeast RNA polymerase II core subunit, Rpb4, in stress and nonstress conditions. J. Biol. Chem. 278: 3339-3346.

Rosenheck, S. and Choder, M. 1998. Rpb4, a subunit of RNA polymerase II, enables the enzyme to transcribe at temperature extremes in vitro. J. Bacteriol. 180: 6187-6192.

Ross, J. 1996. Control of messenger RNA stability in higher eukaryotes. Trends Genet. 12: 171-175.

Sachs, A.B. and Davis, R.W. 1989. The poly(A) binding protein is required for poly(A) shortening and 60S ribosomal subunitdependent translation initiation. Cell 58: 857-867.

Schwartz, D.C. and Parker, R. 1999. Mutations in translation initiation factors lead to increased rates of deadenylation and decapping of mRNAs in Saccharomyces cerevisiae. Mol. Cell. Biol. 19: 5247-5256.

Sheffer, A., Varon, M., and Choder, M. 1999. Rpb7 can interact with RNA polymerase II and support transcription during some stresses independently of Rpb4. Mol. Cell. Biol. 19: $2672-2680$.

Sheth, U. and Parker, R. 2003. Decapping and decay of messenger RNA occur in cytoplasmic processing bodies. Science 300: 805-808.

Tan, Q., Li, X., Sadhale, P.P., Miyao, T., and Woychik, N.A. 2000. Multiple mechanisms of suppression circumvent transcription defects in an RNA polymerase mutant. Mol. Cell. Biol. 20: 8124-8133.

Teixeira, D., Sheth, U., Valencia-Sanchez, M.A., Brengues, M., and Parker, R. 2005. Processing bodies require RNA for assembly and contain nontranslating mRNAs. RNA 11:371382.

Tharun, S. and Parker, R. 2001. Targeting an mRNA for decapping: Displacement of translation factors and association of the Lsm 1p-7p complex on deadenylated yeast mRNAs. Mol. Cell 8: 1075-1083.

Tharun, S., He, W., Mayes, A.E., Lennertz, P., Beggs, J.D., and Parker, R. 2000. Yeast Sm-like proteins function in mRNA 
Lotan et al.

decapping and decay. Nature 404: 515-518.

Tucker, M., Valencia-Sanchez, M.A., Staples, R.R., Chen, J., Denis, C.L., and Parker, R. 2001. The transcription factor associated Ccr4 and Caf1 proteins are components of the major cytoplasmic mRNA deadenylase in Saccharomyces cerevisiae. Cell 104: 377-386.

Tucker, M., Staples, R.R., Valencia-Sanchez, M.A., Muhlrad, D., and Parker, R. 2002. Ccr4p is the catalytic subunit of a Ccr4p/Pop2p/Notp mRNA deadenylase complex in Saccharomyces cerevisiae. EMBO J. 21: 1427-1436.

Uetz, P., Giot, L., Cagney, G., Mansfield, T.A., Judson, R.S., Knight, J.R., Lockshon, D., Narayan, V., Srinivasan, M., Pochart, P., et al. 2000. A comprehensive analysis of proteinprotein interactions in Saccharomyces cerevisiae. Nature 403: 623-627.

van Dijk, E., Cougot, N., Meyer, S., Babajko, S., Wahle, E., and Seraphin, B. 2002. Human Dcp2: A catalytically active mRNA decapping enzyme located in specific cytoplasmic structures. EMBO J. 21: 6915-6924.

Vinciguerra, P. and Stutz, F. 2004. mRNA export: An assembly line from genes to nuclear pores. Curr. Opin. Cell. Biol. 16: $285-292$.

Wang, Y., Liu, C.L., Storey, J.D., Tibshirani, R.J., Herschlag, D., and Brown, P.O. 2002. Precision and functional specificity in mRNA decay. Proc. Nat1. Acad. Sci. 99: 5860-5865.

Warner, J.R. 1999. The economics of ribosome biosynthesis in yeast. Trends Biochem. Sci. 24: 437-440.

Warner, J.R., Vilardell, J., and Sohn, J.H. 2001. Economics of ribosome biosynthesis. Cold Spring Harbor Symp. Quant. Biol. 66: 567-574.

Wilusz, C.J. and Wilusz, J. 2004. Bringing the role of mRNA decay in the control of gene expression into focus. Trends Genet. 20: 491-497.

Wilusz, C.J., Wang, W., and Peltz, S.W. 2001. Curbing the nonsense: The activation and regulation of mRNA surveillance. Genes \& Dev. 15: 2781-2785.

Woychik, N.A. and Young, R.A. 1989. RNA polymerase II subunit RPB4 is essential for high- and low-temperature yeast cell growth. Mol. Cell. Biol. 9: 2854-2859.

Yin, Z., Wilson, S., Hauser, N.C., Tournu, H., Hoheisel, J.D., and Brown, A.J. 2003. Glucose triggers different global responses in yeast, depending on the strength of the signal, and transiently stabilizes ribosomal protein mRNAs. Mol. Microbiol. 48: 713-724.

Young, R.A. 1991. RNA polymerase II. Annu. Rev. Biochem. 60: 689-715.

Zhang, S., Williams, C.J., Hagan, K., and Peltz, S.W. 1999. Mutations in VPS16 and MRT1 stabilize mRNAs by activating an inhibitor of the decapping enzyme. Mol. Cell. Biol. 19: $7568-7576$. 


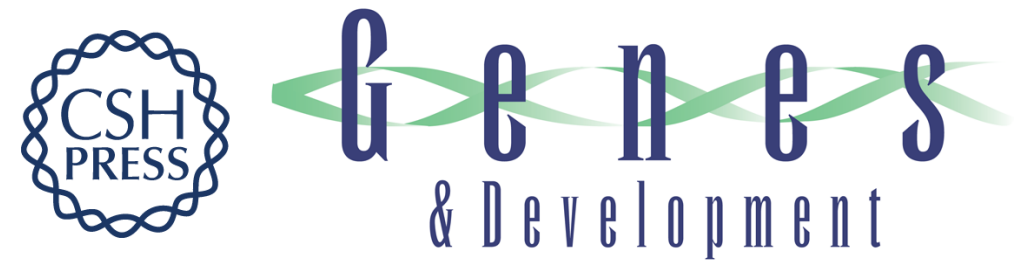

\section{The RNA polymerase II subunit Rpb4p mediates decay of a specific class of mRNAs}

Rona Lotan, Vicky Goler Bar-On, Liat Harel-Sharvit, et al.

Genes Dev. 2005, 19:

Access the most recent version at doi:10.1101/gad.353205

\section{Supplemental http://genesdev.cshlp.org/content/suppl/2005/11/30/19.24.3004.DC1 Material}

References This article cites 65 articles, 33 of which can be accessed free at: http://genesdev.cshlp.org/content/19/24/3004.full.html\#ref-list-1

\section{License}

Email Alerting

Receive free email alerts when new articles cite this article - sign up in the box at the top Service

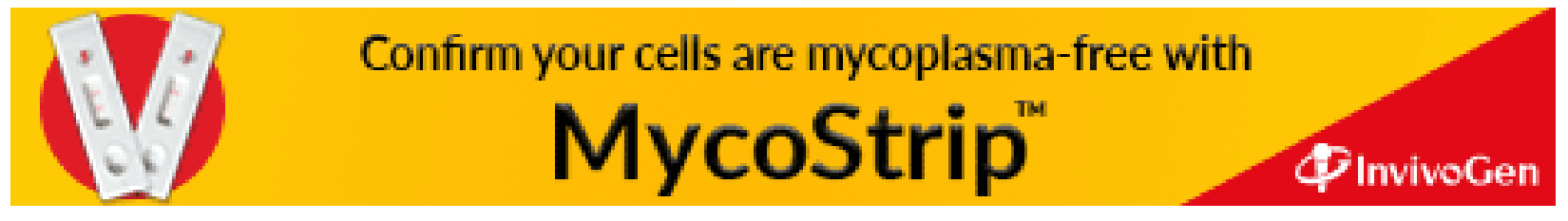

